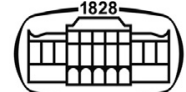

AKADÉMIAI KIADÓ

Pollack Periodica

An International Journal

for Engineering and

Information Sciences

16 (2021) 3, 151-157

DOl:

10.1556/606.2021.00397

(C) 2021 The Author(s)

\section{ORIGINAL RESEARCH PAPER}

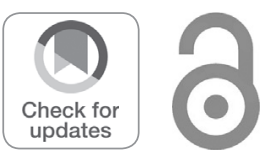

*Correspondingauthor.

E-mail: ohyeahwmy@gmail.com

\section{AKJournals}

\title{
The impact of social interaction on the leftover space
}

\section{Mengyang $\mathrm{Wu}^{1 *}$ ๑( ) and Bálint Bachmann ${ }^{2}$}

\author{
${ }^{1}$ Marcel Breuer Doctoral School, Faculty of Engineering and Information Technology, University of \\ Pécs, Boszorkány u. 2, H-7624 Pécs, Hungary \\ ${ }^{2}$ Faculty of Engineering and Information Technology, Institute of Architecture and Urban Planning, \\ University of Pécs, Boszorkány u. 2, H-7624 Pécs, Hungary
}

Received: January 11, 2021 • Revised manuscript received: April 21, 2021 • Accepted: April 22, 2021 Published online: May 29, 2021

\begin{abstract}
With the rapid economic development, the original layout structure and spatial functions of the city have been affected. The purpose of this paper is to stimulate the potential and vitality of space through social interaction based on the analysis of activity behavior and traffic travel. Through communication in the existing leftover space, a living community with the purpose of spatial emotional connection is established or reconstructed. The social habits of residents have also undergone many adjustments and reorganizations. In this way, the degree of connection between people and space is deepened, to guide the public to actively participate in the adjustment of the characteristics of leftover space and space optimization, broaden the application boundary of space.
\end{abstract}

\section{KEYWORDS}

leftover space, social interaction, public participation, community

\section{INTRODUCTION}

The essence of a city is the gathering of people. The city comprehensively reflects the development process of society and the level of material and spiritual civilization [1]. With the information technology revolution and economic globalization, the spatial form and structure of cities have undergone tremendous changes. The technological revolution based on information technology has brought about subversive changes in the structure of social production, consumption structure and people's lifestyle. Mechanized and information-based production methods have greatly improved production efficiency, which has also divided social production increasingly refined. The well-developed transportation network and information dissemination enable production to be dispersed, and reasonable distribution and layout in different urban spaces. The popularization of e-commerce and the improvement of logistics systems have also turned part of the traditional physical consumption space into virtual consumption space, which has promoted the emergence of some new urban space types. With the renewal of cities, the original urban industrial areas, old urban areas, urban infrastructure areas have all disintegrated to varying degrees [2]. Due to its space restrictions and location factors, a large part of the area cannot get enough attention and economic investment, nor can it become a part of urban life, so it gradually becomes the leftover space of the city.

Although the world is undergoing a large-scale urbanization process, "urban shrinking" has also become a tributary of development. While urban shrinkage has caused many potential problems, including infrastructure redundancy and various social problems, a single issue often becomes the focus of action. That issue is the problem of vacant or abandoned housing [3]. The material existence of the city, especially the rich social and cultural connotations carried by the urban space, is gradually being swallowed and forgotten by the enthusiasm and restlessness of development. 


\subsection{Leftover space}

The concept of the term "leftover space" was originally thought of as an extra layer of space exists between the exterior and the interior, and this type of "extra area" was called leftover space in 1977 [4]. Japanese architect Yoshinobu Ashihara defined unplanned, chaotic space or planned space with neglect of humanity as "negative space" in 1985 [5, pp. 30-33]. In 1996, the direction of the research has been more closely related to the city. In the process of solving the limitations and potential of urban design, urban cracks have proved to be the key factor leading to the creation of leftover space. Every city has its cracks, which are the gaps of the urban form, the physical divides that purposefully or accidentally separate social worlds, and the overall continuity is disrupted [6, pp. 91-92]. Urban leftover space was interpreted as redundant and abandoned urban space [1, pp. 114-115]. Any type of urban space contains or produces leftover space. This is a form of existence of urban evolution. This type of space is easily ignored by users and cannot fully utilize its potential value. Combining the discussion of space models in the past, the leftover space can be further explained as that with the development and reorganization of cities, this type of space gradually appears inconsistent with urban development, leading to temporary stagnation or interruption of people's internal behavior and social activities because of the demand for this type of space. And since participation is reduced to nowhere, the ability to communicate with the outside world is often ignored.

\subsection{Community}

"Community" is a concept of space, a place where people compete and cooperate for survival, and the ecological dimension of social life [7, p. 181]. The social connection of human beings in the sense of space is manifested in three variables: scale, density and heterogeneity. The differences in these aspects of space will affect the actions of people in their lives [8]. Some scholars have proposed a more systematic spatial interpretation model. For example, the types of space restrictions on movement can be summarized as: high density-high partition, high density-low partition, low density-high partition, and low density-low partition. Produce different types of social actions. For example, in the first type of space, it is easy to form a cohesive "strong relationship" interaction, because the high degree of homogeneity makes information dissemination very smooth, which helps people form a more intimate interaction structure; but dense populations are bound to the similar structure as other types of interactions. The formation of dense communication nodes eliminates the need for actors to seek out new information and social relations, thereby strengthening the cohesion of communication [9]. Abbott proposed a more complete "situationist" methodology. He believes that the situations that affect social actions can be divided into three levels according to complexity: natural area, area-careers and interactional-field. The "natural area" is a specific space with clear geographical boundaries and its own cultural tradition, which can be regarded as a sliced spatial context. The "areacareers" mainly incorporates the diachronic nature of space and the influence of external space on it, and can be seen as a spatial context integrated into the time dimension. The "interactional-field" goes a step further, considering the relationship between multiple time and space at the same time, which is the real situation in social interaction [10]. Giddens believes that social interaction is carried out in the "locale", which refers to the use of space to provide various scenarios for interaction, and the interactive scenarios constitute the contextual factors that limit the interaction [11, p. 111]. "Locale" implies that space is a constituent element of interaction, which is different from place. "Place" only describes the spatial parameters or physical environment where the interaction occurs [12, p. 220].

\subsection{From leftover space to active community}

This article is guided by the core of community building and social interaction as the channel. It aims to build a community collection in the leftover space, allowing the public to participate in the design or activities of the block, establishing a sense of social identity, and emphasizing that it is the cultural cohesion and sense of belonging among members of the "community of life". As the frequency of interaction increases, residents establish close social connections with each other and with the surrounding community [13]. The core of community empowerment is human beings and the purpose is not only to create a community, but more importantly is to cultivate people's behavior and habits, actively participate in public services, and create a community's humanistic emotions. The quality of leftover space is optimized in the interaction and feedback of participants. The concept of this research is to find the formation and connection of space from the behavioral route and traffic travel analysis of the activity. In the whole process, multisubject participation allows social interaction to stimulate the utilization of leftover space.

\section{METHODOLOGIES}

\subsection{Activity-based behavior analysis - the formation of a spatial system}

Urban residents need to participate in activities that generate demands for different spaces, which should be the foundation of the formation of the spatial system and urban planning. Outdoor activities can be divided into three categories of outdoor activities which are necessary, optional, and social activity [14]. Necessary activities would occur in every type of conditions. Optional activities occur when there is a willingness to participate and when it is conducive to participating in these activities. Social activities are "resultant" because as long as the conditions for necessary activities and spontaneous activities in public spaces are improved and the social activities will be more effective. The round trip theory is an influential tool to explain travel 


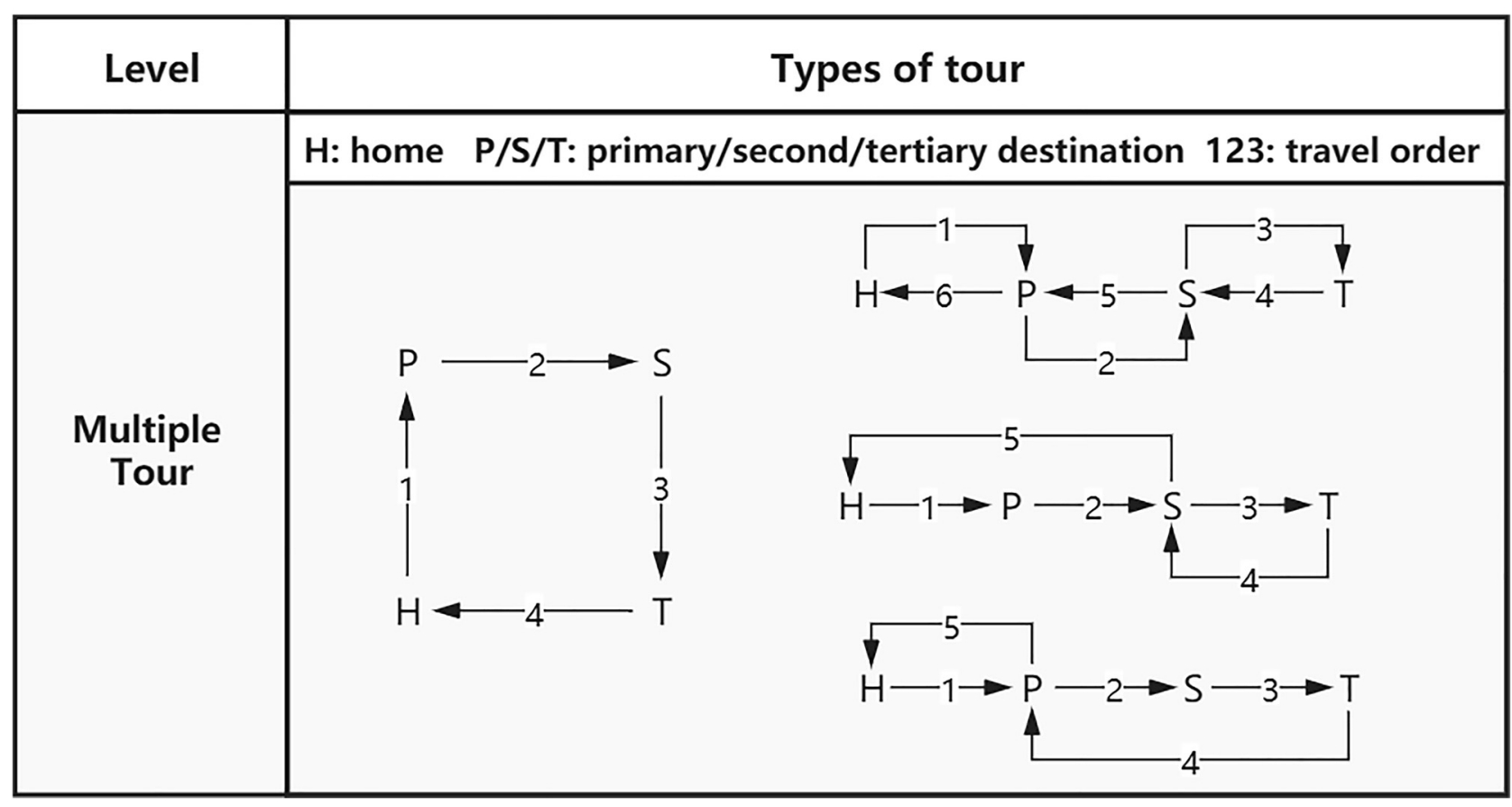

Fig. 1. Route selection types for multiple tour.

(Source: designed by M. Wu)

behavior and is based on the activity chain method. The reason why a group of trips can be considered as a round trip is because all trips can be regarded as home-based circular trips, which include stop locations and travel destinations and corresponding quantity. As it is shown in Fig. 1, there is a priority ordering problem between the respective destinations of travel. The first step in ranking is to find the most important travel destination, which is the "main" destination. From this point of view, other secondary destinations exist on the condition of the primary destination. Any trip with multiple stopovers has a primary activity and main destination, which also constitutes the principal motivation for the trip. It also occupies a decisive position in determining travel frequency, mode, time and even route.

From the perspective of residents' personal lives, the urban activity system is composed of various daily activities of urban residents, and the spatial scope of these activities constitutes the travel-activity system. This system is different from the traditional urban physical space system. As it is shown in Fig. 2, it emphasizes the active behavior of urban residents, which is a behavioral space system formed when residents use urban facilities and participates in social organizations.

Introducing residents' activities is one of the more effective channels to update the leftover space and adjust the leftover attributes. By introducing dynamic activities into the (temporarily) static leftover space, by increasing the number of participants and the frequency of space use, the leftover space can be gradually activated. Through the analysis of different patterns of behavior, space is associated with this in a targeted manner. This involves moving the activity pattern closer to space, once again thinking and feeling the potential characteristics of the space, and stimulating the internal regional vitality through external variable factors. On the other side, the introduction of urban activities according to local conditions will help connect the leftover space with the surrounding urban environment, and promote the interaction between the building and the city.

\subsection{Traffic travel analysis of activity behavior - establishing connections between spaces}

The occurrence and connection of residents' activity behaviors can be progressed through movement, which is traffic behavior. Spaces of different attributes are connected in series during traffic travel. Therefore, as a dynamic link within the urban residents' behavioral systems, mobile behavior is the key to understanding the urban activitytravel system. In traditional transportation and travel research and models, the common method is to achieve travel demand through the development and supply of quantitative transportation facilities, the relationship between travel and activities is easily overlooked. However, starting from activities, considering the interrelationship between activities and the intention and diversification of transportation in it, the transportation demand can be fundamentally grasped. Based on the establishment and optimization of the activity model, the corresponding space between travelers and their own needs is constructed more clearly [16]. This model optimizes the interactive relationship between the spatial layout of urban functions and urban transportation, and also integrates the urban space of transportation travel, social and economic factors and other travel backgrounds, and builds flexible control of urban 


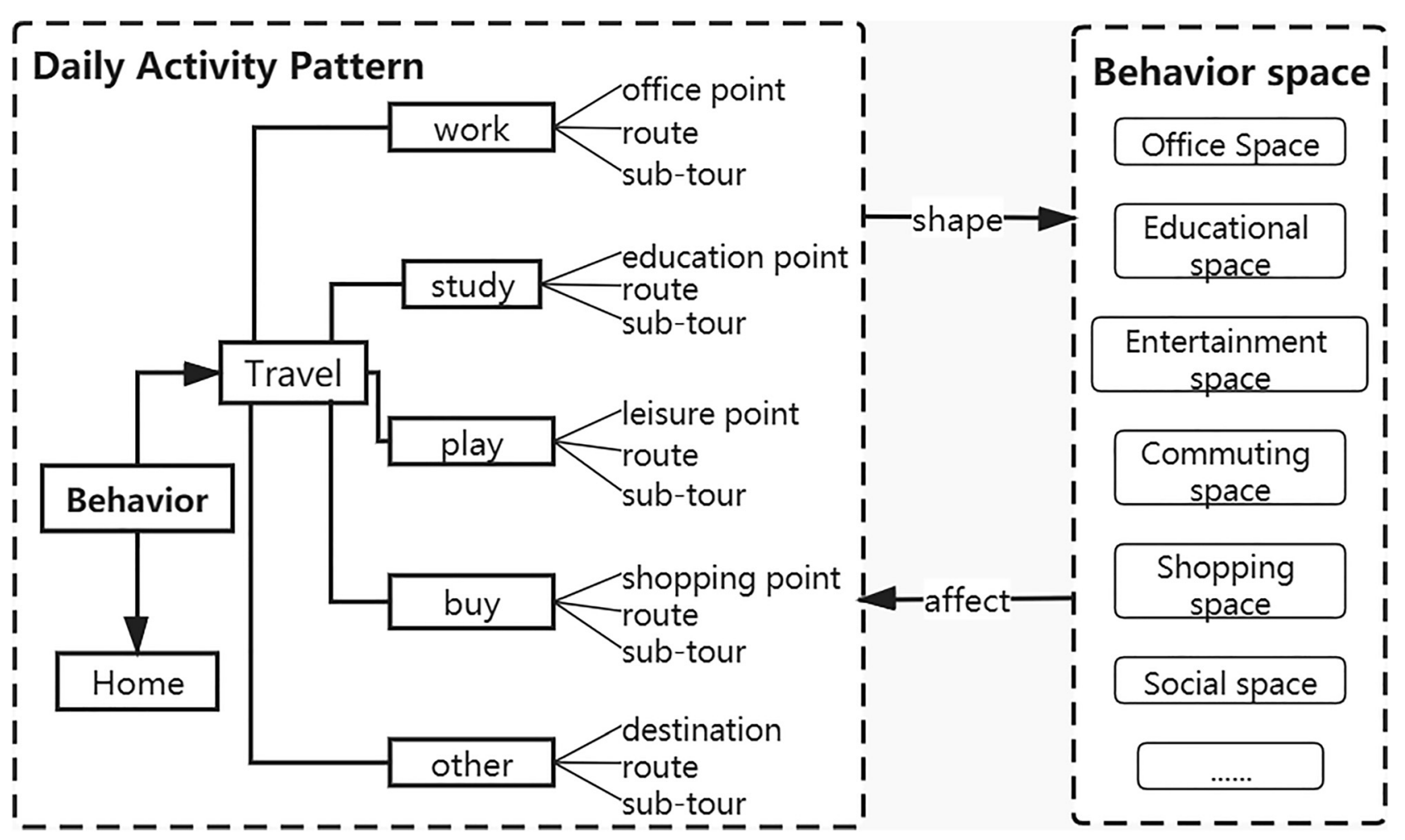

Fig. 2. Flow of daily activity pattern and behavior space generation [15].

(Source: designed by M. Wu, based on J.L. Bowman and M.E. Ben-Akiva)

demand management. The study of the urban activity-travel system not only emphasizes the analysis of citizen travel from the perspective of personal behavior decision-making, and reflects the continuity of activities and travel through short-term changes in the time dimension of daily activities, but also emphasizes the periodicity of travel activities and the use of traffic space in the time dimension of daily activities.

The Underline project in Miami is a 10-mile (about 16.1 $\mathrm{km}$ ) long park and trail that is located below the Metrorail guideway, from the Brickell Backyard to the Dadeland South Metrorail Station [17]. The project is initiated and led by a non-profit organization run by community activists, which aims to reimagine the intervention in blind areas under the railway tracks. As it is shown in Fig. 3, The Underline is built in three phases. The first phase is currently open to the public in February 2021 [17]. It features a walkable and bikeable corridor that brings together spaces for recreation, exploration and relaxation, and improves connectivity between the surrounding communities. The previously unpopular road has been transformed into a vibrant street, with a people-oriented renovation plan that has won the city a new public space. Driven by an instinct for nature, designers are thinking about how to build more public spaces based on the existing urban environment. The original intention of The Underline project was to optimize the vacant space beneath existing infrastructure to create a pleasant and energetic environment. Through the redistribution of the leftover space, a harmonious integration between the transportation infrastructure and the public space is created, from the activities of people to the connection of the site, the functions are refined and reorganized again, resulting in a more appropriate embedding in the urban texture.

Urban development has resulted in reinforced concrete structures compressing the natural space of the original land. Urban issues of the lack of green space and social space have promoted the innovative transformation. This urban renovation strategy encourages citizen participation with an open attitude. For those who stay in the square for activities, a variety of alternative paths bring them different surprises. The former "No-man's land" has become a comfortable square. The noise of the car was replaced by the laughter of children playing, relaxed conversations in the neighborhood and happy games from the residents.

\subsection{Multi-subject participation - Social interaction behaviors stimulate spatial potential and vitality}

The urban leftover space involves multi-participation in social interactions, which can establish a balance of interests, and stabilize in mutual restraint. The joint participation of the government, developers, designers, and the public of different professions can provide multi-dimensional thinking directions for awakening the urban leftover space and shape the diversity of the space environment (Fig. 4). Additionally, the public actively participates in the design of the leftover space, which is an indispensable part of the development and maintenance of the leftover space. In the process of participation, it cultivates the public's awareness 


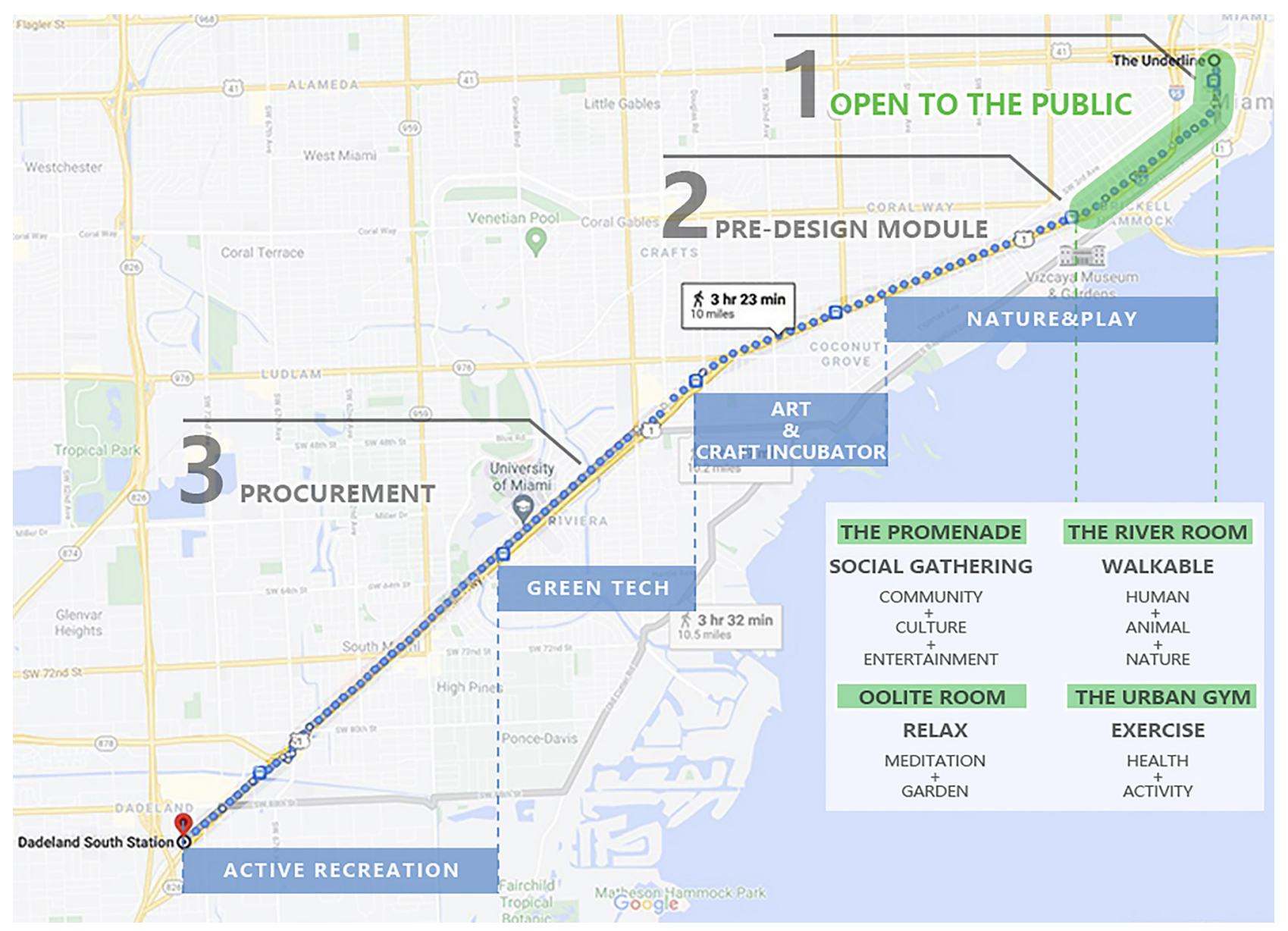

Fig. 3. The underline function distribution route map [17].

(Source: designed by M. Wu, based on James Corner Field Operations)

of paying attention to the leftover space around them, paving the way for in-depth public participation.

The vitality of space means that the environment not only caters to the physical and psychological needs of users, but also promotes the generation of diversified activities in the space, achieves efficient use of environmental space, enhances the public's sense of belonging to the place, then presents a uniquely charming place environment and social significance [18]. The potential and vitality of developing leftover space lie in the people in it and their social activities. The experiencers develop and participate in activities in it, which is the fundamental factor of the decision.

Except for the "leftover" of space caused by political systems and planning regulations, the formation of this type of space is mainly due to the separation of its relationship with people. The urban leftover space is public, which means it is an area shared by the public. The space is guided by the current and future needs of the public, and the "intervention points" of the urban leftover space are gradually clarified with the participation of multiple parties. Establishing public opinion research workshops is one of the ways to directly understand users' thoughts, combining the spatial needs of local residents' lifestyles and transformation intentions, and focusing on enriching the attributes of the leftover space, thereby optimizing people's activities.

\section{DISCUSSION AND CONCLUSIONS}

The leftover space serves as a buffer area to accommodate growth possibilities, although scholars have different evaluations of leftover space in recent years. However, the author believes that from the time dimension combined with the overall urban planning, its positive potential will far exceed the current negative attributes. At the same time, we can imagine that if every space in the city is under strict control for a long time, then the city may be in a tight and dense state. This state is vigorous but not balanced. The existence of leftover space may provide a "breathing" space for the city.

This article analyzes the urban leftover space from the perspective of social interaction, and establishes social flexibility through external intervention and internal guidance. In this way, the "leftover" boundary is extended and the adjacent space functions are stitched together. It mainly 


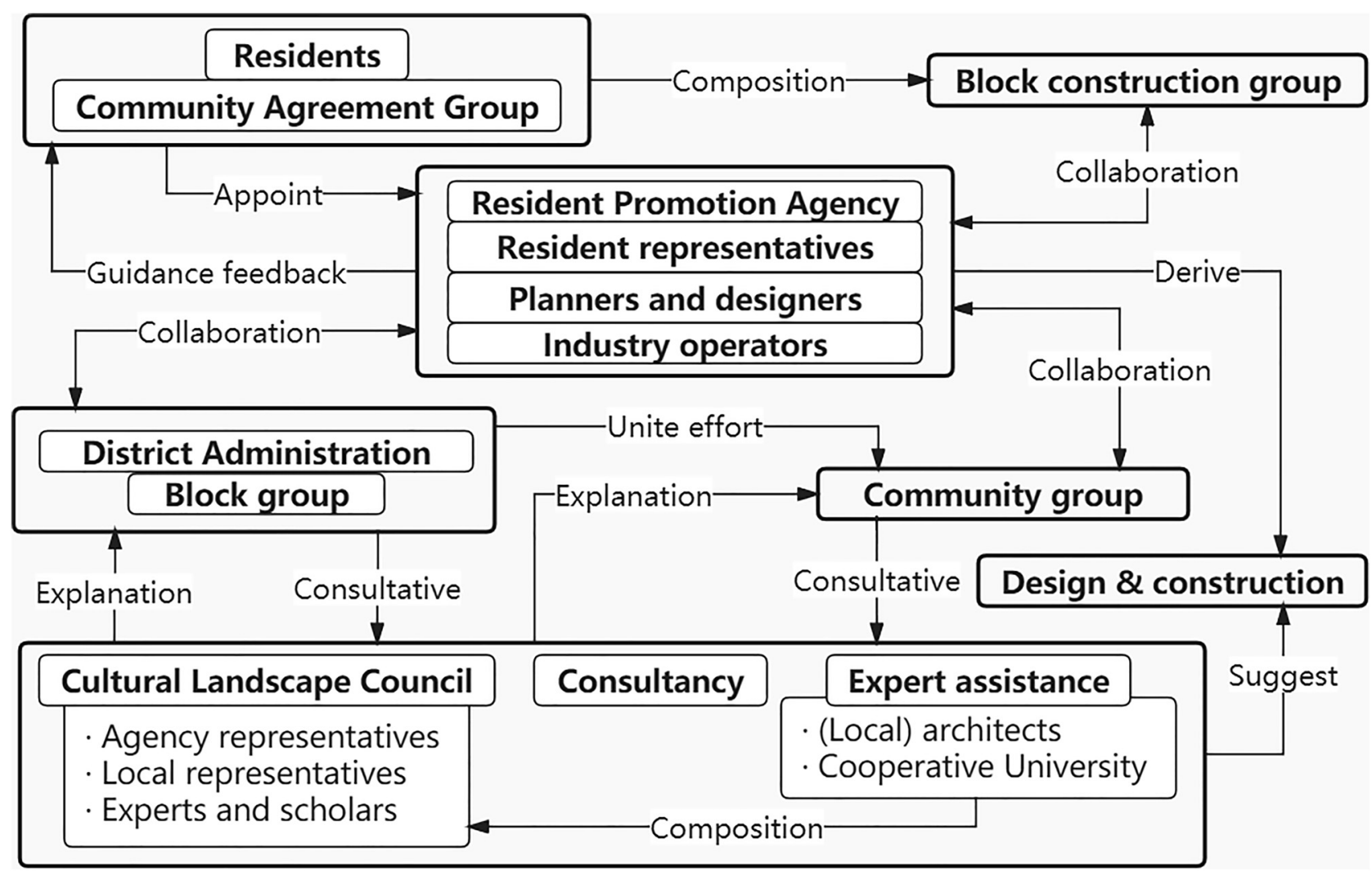

Fig. 4. Participation of multiple subjects: the promotion system of block construction. (Source: designed by M. Wu)

involves the comprehensive design of space function and environment, creating high-quality communication space and multi-level activity space. The construction of multiple functions is conducive to increasing people's interaction in the space, promoting the emotional connection between people and space in the experience, and forming a sense of belonging. Under the diversified behavioral needs of the public, the functional design of urban leftover space also tends to be mixed, that is, urban leftover space can meet other types of needs while meeting basic behavioral needs. The "fuzzy" processing of the space boundary makes each area of the space more flexible and produces diverse interactions. In addition, this is to link and combine smallscale intervention with large-scale strategies to guide the public to actively participate and awaken the vitality of the remaining urban space.

From the perspective of the analysis workflow, it is the "point" of social interaction that radiates to the "surface" of spatial update. This article advocates paying attention to the urban leftover space in daily life, as a catalyst for restoration, which ultimately affects people's life and communication. Through the construction of a multi-participation mechanism, the public is guided to switch from the role of "bystander" to "participant", promote interaction in the process of participation, strengthen the relationship between the outside world and the leftover space, and expand the social function of "leftover".
Research on urban development is a continuous task, and it is necessary to continue to consult materials and participate in actual research. There are many topics that can be discussed in more depth. In order to further understand these possibilities and opportunities, I hope that more forces will participate in this research project in the future.

\section{REFERENCES}

[1] L. Xiaodong and Z. Ye, "Urban leftover space" (in Chinese), World Architect, no. 1, pp. 114-116, 2009.

[2] D. Lijing, "The social space reconstruction during the renewal and reconstruction of old industrial city," Future Dev., vol. 38, no. 10, pp. 17-21, 2014.

[3] A. Mallach, A. Haase, and K. Hattori, "The shrinking city in comparative perspective: Contrasting dynamics and responses to urban shrinkage," Cities, vol. 69, pp. 102-108, 2017.

[4] R. Venturi. Complexity and Contradiction in Architecture. New York: The Museum of Modern Art, 1977.

[5] Y. Ashihara (Author) and Y. Peitong (Translater), Exterior Design in Architecture (in Chinese). Beijing: China Architecture \& Building Press; 1985.

[6] A. L. Sideris, "Cracks in the city: Addressing the constraints and potentials of urban design," J. Urban Des., vol. 1, pp. 91-103, 1996 
[7] R. E. Park, Human Communities: The City and Human Ecology. London: Collier-Macmillan, 1952.

[8] L. Wirth, "Urbanism as a way of life," Am. J. Sociol., vol. 44, no. 1, pp. 1-24, 1938

[9] M. Wirth, "Toward a sociology of space: The constrained choice model," Symbolic Interact., vol. 5, no. 1, pp. 65-78, 1982.

[10] A. Abbott, "Of time and space: The contemporary relevance of the Chicago school," Soc. Forces, vol. 75, no. 4, pp. 1149-1182, 1997.

[11] A. Giddens (Author), L. Kang, and L. Meng (Translater), The Constitution of Society: Outline of the Theory of Structuration (in Chinese). Beijing: China Renmin University Press, 2016.

[12] A. Giddens (Author), G. Zhonghua, and X. Fayin (Translater), Central Problems in Social Theory: Action, Structure, and Contradiction in Social Analysis (in Chinese). Shanghai: Shanghai Translation Publishing House, 2015.
[13] M. Xiaoxiao and M. Liang, "The experiences and Inspirations of community building in Taiwan," Urban Dev. Stud., vol. 23, no. 1, pp. 91-96, 2016.

[14] J. Gehl, Life between Buildings: Using Public Space. London: Island Press, 2011.

[15] J. L. Bowman and M. E. Ben-Akiva, "Activity-based disaggregate travel demand model system with activity schedules," Transport. Res. A: Pol. Pract., vol. 35, no. 1, pp. 1-28, 2001.

[16] M. Juhász, "Development of a land-use and transport interaction model as a part of a policy assessment framework for urban traffic calming," Pollack Period., vol. 10, no. 2, pp. 81-92, 2015.

[17] The underline, Phases. [Online]. Available: https://www. theunderline.org/phases/. Accessed: Apr. 20, 2021.

[18] H. Zuo, "Principles for creation of key element for inspiring the vigor in urban public space," Chin. Overseas Architect., no. 2, pp. 66-67, 2010. 